$\xi=-1$

\title{
Fostering interests for teaching: Job satisfaction and motivation fators of Malaysian TVET instructors
}

\author{
Muhd Khaizer Omar', Abdullah Mat Rashid ${ }^{1}$, Mohd Hazwan Mohd Puad ${ }^{1}$, Ady Hameme Nor Azman ${ }^{1}$ \\ ${ }^{1}$ Universiti Putra Malaysia \\ *Corresponding author E-mail: khaizer@upm.edu.my
}

\begin{abstract}
Often, when the public is asked of what teachers normally do in class, the most common response would be: What else will they do? Teaching students is their core business. In general, the role of teachers in school is restricted to the traditional conception of what teachers should teach. Undoubtedly, the notion of 'to only teach' was relevant in the last thirty years unlike now. With respect to this matter, this study explored the reasons why some teachers retain while some leave this noble profession based on previous studies. Also, Adam's Equity Theory (AET) of motivation was examined. Essentially, the theory served as a guideline for the researchers to ascertain the job satisfaction factors that contributed to the narratives of TVET instructors with regards to their reasoning process. Notably, the research was carried out using a mixed-method design which employs a convergent parallel design. For the purpose of this article, the results were derived from the narrative section through an online survey named Qualtrics. The population of this survey comprised of Malaysian training instructors at the Technical and Vocational Education and Training (TVET) educational institutions. In addition, a thematic analysis using the Atlas.ti software was employed to determine the reasons of TVET instructors retaining in the teaching profession and to identify the contributing factors of job satisfaction. Based on the findings, six themes with regards to teaching job satisfaction factors of TVET instructors were identified: conducive working environment, deep interest towards teaching profession, performing tasks well, satisfactory achievement among students, student factor, and students' understanding during class. Ultimately, the understanding of teaching job satisfaction among TVET instructors can be construed as an eye-opener to enhance teaching motivation in alignment with the overarching advancement of this field.
\end{abstract}

Keywords: Technical and Vocational Education and Training (TVET), Job Satisfaction, Retention, Motivation.

\section{Introduction}

Basically, as stated in Budget 2018 which was presented by the former Prime Minister of Malaysia Dato' Seri Mohd Najib Bin Tun Abdul Razak, RM4.9 billion was allocated to implement the Master Plan of TVET Malaysia to strengthen TVET education in Malaysia. Undeniably, this provision was perceived as uplifting and an opportune moment to rebrand TVET in Malaysia. Clearly, this initiative to rebrand TVET Malaysia accentuates the government's effort in producing skilled and highly educated people in the field. At this juncture, progressive support is necessary to further consolidate the government's effort in providing opportunities for individuals who struggled academically in the technical field. Besides, the integration of Industrial Revolution 4.0 in Malaysia's TVET ensures that the country is on track to achieve the status of a developed nation by 2050 . Generally, TVET Malaysia was established by the government to equip students with theoretical and practical training before entering into the working environment. In line with the progress of industrialization, TVET Malaysia highly emphasizes on producing competent graduates who possess exceptional market value. Undoubtedly, this strategy creates opportunities for employment among graduates in Malaysia and abroad. However, the strategies to embellish the image of TVET in Malaysia would be futile if the instructors at the institution fail to deliver the task. Besides, the success of TVET would be jeopardized if the instructors are belittled by authoritarians who practice workplace politics, thus affecting the role of TVET instructors as teachers. Even though TVET instructors may have remarkable portfolios, due to their years of technical experience, some may only gain teaching experience after a period of time.

Furthermore, TVET instructors who mainly teach technical subjects might struggle different issues as compared to traditional teachers. As indicated by previous researchers, teachers' retirements, relocations, and changes of career [1, 2, 3, 4] were among the main reasons for teachers leaving the teaching profession. However, it should be noted that the number of research pertaining specifically to TVET teachers, vocational teachers, and career and technical educators remains insignificant. Also, other reasons for teachers' dropout discovered were, namely politics of schooling, time demands, low salaries, few benefits, little opportunity for advancement, excessive workloads, high-stakes testing, long working hours, disruptive student behavior, poor leadership and administration within schools, perception of teaching as a temporary profession, and frustrations associated with trying to motivate apathetic students $[1,2,4,5,6,7,8,9]$.

Notably, all the stated reasons did not represent TVET instructors in general. In this paper, the analysis of job satisfaction factors was conducted alongside justifications in narrative form. To begin, Adam's Equity theory was employed to determine the power play by both extrinsic and intrinsic factor that embolden instructors' decision. Ultimately, the meaning-making and dialectical approach in the narrative form of the educational stakeholders, TVET instructors, and education division at different levels were taken into consideration. Then, a conclusion was drawn concern- 
ing the decision in order to ensure the significance of TVET instructors is well-sustained and maintain the integrity of teaching as a noble profession.

\section{Issues pertaining teachers job satisfaction and retention}

Inevitably, teachers who teach technical subjects (ie., welding, culinary arts, hospitality, technical drawing) are crucial in ensuring the longevity of the TVET system in the educational paradigm. In fact, through the retainment of TVET, teachers will be empowered to expand the nation's capacity to provide technical and vocational knowledge to the future generation. With regards to the TVET education, its pragmatic approach is influenced by the experience possessed by teachers before being transmitted to students. In this context, most of TVET instructors have had several years of industrial experiences, thus making them a valuable asset in the TVET system.

Moreover, TVET instructors as teachers aspire to elevate students' academic achievement in order to increase excellent human capital for the nation. However, the flagrant issue of teachers' dropout is evident in some countries, and findings have indicated various predictable factors pertaining to teachers leaving the teaching profession. In specific, job satisfaction and retention of teachers are concurrently and meticulously being researched in academia to ensure the quality of teachers at schools is fulfilled [2, 8]. Undeniably, the compulsion of guaranteeing the quality of teaching and learning experience that includes school performance and students' academic performance coerce teachers to meet high standardization and manage accountability issues. In relation to this matter, teachers struggle with tons of administrative tasks which outweigh their core business which is to teach. Subsequently, the pressure of unnecessary assignments and workloads resulted in a change of career among teachers and even worse, some decided to leave the workforce entirely [8]

Additionally, the acrimonious environment of school was depicted by Mertler [8] through the reference of some extrinsic factors such as the less attractive remuneration package of teaching scheme and teaching incentive offered. Interestingly, the multiple reasons for teachers' attrition include teachers' localities and influence of socio-economic status. A study by Gomba [2] listed five factors that encourage teachers to continue teaching: (a) need to support their families, (b) job security, (c) unmarketable, (d) support from colleagues and administration, and (5) self-sacrifice leadership by principals. From the findings of this study, it is apparent that teachers undergo tremendous stress for the sake of monetary and intrinsic or extrinsic influences. Thus, this troubling matter hinders teachers from realizing their full potential in the profession.

On top of that, working conditions play a very pertinent role in influencing job satisfaction $[10,11]$. To note, employees would attain satisfaction if their workplace is equipped with adequate tools and equipment, and have acceptable levels of environment such as quality, temperature, humidity and noise. Inevitably, an inconducive working environment can often be a cause of low productivity. In order to overcome this situation, employees require adequate equipment, space, heating, lighting, ventilation and color as all of these elements can significantly influence the working environment. Also, restrooms and lockers should be kept clean, secured and well maintained. In terms of welfare management, the food provided for the line employee as for the managers should be similar. Likewise, managers have to trust and reassure their employees even when they fail. In this context, managers are required to formulate a plan which will assist employees in regaining their composure towards succeeding in the future.

Researchers discovered that administrators should encourage teachers to actively collaborate in professional development activities to help develop a learning culture and community [12,
13]. For instance, action research is an important component of teachers' in-service professional development because it allows them to observe and critique their own teaching strategies, connect observation, theory and application in the classroom and causes them to reflect on their efforts. Along this notion, time and administrative support are essential components in the enhancement of teacher's professional development and effectiveness [12]

Particularly, there are three developmental stages that teachers experience as they assimilate into the teaching profession. This includes their concern for survival, concern for self-adequacy, and concern for teaching impact. In this study, mentoring and professional development incentives were identified as factors which encourage new teachers as well as experienced teachers to remain in the working environment. Based on the statistics presented, it is crucial to clearly address the teacher turnover problem, professional development offerings, and discover the most effective strategies needed to hire and retain the best performing teachers of public, private and Christian based schools through the United States.

In actuality, some researchers have investigated the underlying reasons of teacher attrition. For instance, Provasnik and Dorfman examined the teacher workforce and the movement of teachers in and out of the workforce. One of the major concerns is the lack of highly qualified teachers would result in students with disabilities receiving inadequate service, thus potentially resulting in poor educational outcomes. Besides, shortage of teachers will sometimes eventuate to administrators hiring less qualified teachers. Worryingly, individuals who lack qualification than teachers with years of teaching experience are more likely to be absorbed into the teaching force.

To reiterate, the deleterious effect of teachers' dropout require specific and undivided attention. Undeniably, the growth of a nation is dependent on the retainment of competent teachers which provides quality educational experience. As a matter of fact, researches have been conducted to overcome the increasing quantity of teachers' dropout. In the hope of preventing marginalization of a particular group of educators from the teaching society, this research seeks to take into account of TVET instructors' perspectives when determining teaching job satisfaction factors.

\section{Research objective}

In this paper, Adam's Equity Theory (AET) of motivation was analyzed through the narrative information of Malaysian TVET instructors' teaching job satisfaction. To elaborate on the meaning of teaching job satisfaction, the famous Maslow and Herzberg theory of motivation was introduced. Then, emerging themes were studied through Adam's lens. Subsequently, the interpretations of the analysis were presented to students at university level, educators, and TVET division at ministry level. In this context, conclusions were drawn with respect to the implementation of an improved curriculum and policy on pre-service teaching practices among TVET instructor and understanding the needs from the stakeholders' perception. Ultimately, this study is primarily conducted to determine the job satisfaction factors of Malaysian TVET instructors.

\section{Theoretical perspective}

In general, a series of adaptation of Adam's Equity Theory of motivation has led to the development of a theoretical framework to investigate job satisfaction and retention of TVET instructors' in Malaysia. As a matter of fact, this theory is an extension of the existing theories of Maslow and Herzberg which has highlighted that an individual's motivation is influenced by the state and quality of management. In other words, the higher an individual's impression of the management's fairness, the higher the 
motivation level of the individual, and vice-versa. With regards to the notion of reasonability, workers normally relate their contribution (as far as a commitment) to an outcome or result (as far as remuneration/reward, salary).

Contrastingly, teachers are exposed to the manner in which the school is administered with regards to the context of school environment. Undoubtedly, this includes the perception of students towards them as teachers in the classroom. In actuality, job satisfaction of teachers is frequently measured based on their work outcomes or output, thus influencing their personal growth, career advancement, responsibility, recognition and promotion. Importantly, these issues function as critical 'motivators' to encourage teachers to remain in the teaching profession. Besides, Herzberg underlined that employer's acknowledgement and appreciation can be acknowledged as primary 'motivators'. Undeniably, positive and appropriate management of these motivational factors will result in positive transformations such as equity-supported teaching services, fairness in the school's administration function (i.e. concerning promotion, reward) and enhanced student attitude and behavior (i.e. better performance, less disruptive, increased friendliness). Conversely, if the opposite exists, teachers will be more likely to leave the teaching profession.

\section{Methods}

In this study, the qualitative component of the mixed-methods design was employed. Specifically, this study was conducted using a convergent parallel design where both quantitative and qualitative questions were combined in a single survey instrument. Besides, 'Telegram'(messaging application) was utilized to access the data which contained information regarding the teaching population. To note, 446 teachers who were registered users of "Telegram" from selected 80 TVET institutions in Malaysia were selected to participate in the study. For the purpose of conducting this study, permission was obtained from the Educational Planning and Research Division (EPRD) of Malaysia's Ministry of Education. Additionally, a set of questionnaires and the proposal outlining the purpose of the study were provided to the EPRD as part of the standard procedures required for researching educational institutions in Malaysia.

Precisely, the questions employed for the open-ended feedback section were replicated from a study by Perrachione, Rosser, and Petersen, and Johnsrud and Rosser who studied explicitly on job satisfaction and retention. Besides, an email was sent to the developer to obtain authorization over the use of their instrument. Then, the instrument was distributed using an online survey tool called Qualtrics. Also, the period for data collection was set to occur over a two-month period between November and December 2017. Equally important, three email reminders were sent to the instructors to complete the survey within the specified time allocated.

For the purpose of coding analysis, scripts from typed-data responses were recorded, transcribed, and entered into the Microsoft Excel software. Notably, the application of a qualitative generating software, ATLAS.ti, to analyze the data from the transcription script was closely monitored. Essentially, this measure was taken to ensure that the researchers obtain statements which best describe the participants' answer with regards to the qualitative open-ended questions

For the survey, the respondents were given two choices of either skipping or omitting from answering any question. Respondents were also expected to complete the survey within 30 minutes and were reminded that only one attempt is allowed for the online questionnaire. As a preventive measure, the IP address of the respondent was recorded to avoid respondents from completing more than one questionnaire. Prior to the data transcription process, a professional Malay-to-English translator was hired.

\section{Findings}

In order to investigate the extent of job satisfaction among Malaysian TVET instructors, several close-ended questions were asked during the process of qualitative data collection. All answers were recorded and later analyzed thematically using a CAQDAS, namely ATLAS.ti (version 8). To note, 76 informants were involved in this process. For this study, the data was first recorded in the Malay language and translated into English by an English expert under the supervision of the researchers. Overall, the thematic analysis managed to extract a total number of 208 quotations related to job satisfaction among Malaysian TVET instructors. From the 208 quotations, two main categories and 12 sub-themes were derived. However, for this article, a particular category with six emerging themes on satisfied instructors was expounded. Clearly, the emergence of themes derived from the narrative transcription can be observed from the coding analysis.

The extent of job satisfaction among Malaysian TVET instructors was determined by asking 76 Malaysian TVET instructors several short close-ended questions. A thematic analysis was carried out and a total number of 208 quotations related to the job satisfaction among Malaysian TVET instructors teachers were extracted. Specifically, under the main category of satisfied teachers, six subcategories were obtained; (1) satisfactory achievement among students, (2) conducive working environment, (3) deep interest towards teaching profession, (4) student factor, (5) students' understanding during class, and (6) performing tasks well. Overall, table 1 below illustrates the number of quotations and percentages according to main categories and sub-categories.

Table 1: Number of quotations and percentages according to main categories and sub-categories

\begin{tabular}{|l|l|c|c|}
\hline $\begin{array}{l}\text { Main catego- } \\
\text { ries }\end{array}$ & Sub-categories & $\begin{array}{l}\text { Number of } \\
\text { quotations }\end{array}$ & $\begin{array}{c}\text { Percentage } \\
(\%)\end{array}$ \\
\hline $\begin{array}{l}\text { Satisfied teach- } \\
\text { ers }\end{array}$ & $\begin{array}{l}\text { Conducive working } \\
\text { environment }\end{array}$ & 23 & 11.1 \\
\hline & $\begin{array}{l}\text { Deep interest to- } \\
\text { wards teaching } \\
\text { profession }\end{array}$ & 21 & 10.1 \\
\hline & $\begin{array}{l}\text { Performing tasks } \\
\text { well }\end{array}$ & 30 & 14.4 \\
\hline & $\begin{array}{l}\text { Satisfactory } \\
\text { achievement among } \\
\text { students }\end{array}$ & 40 & 19.2 \\
\hline & Student factor & 11 & 5.3 \\
\hline & $\begin{array}{l}\text { Students' under- } \\
\text { standing during } \\
\text { class }\end{array}$ & 7 & 3.4 \\
\hline
\end{tabular}

\section{Thematic analysis}

Based on the thematic analysis, job satisfaction among Malaysian TVET instructors was discovered to be affected by several aspects: (1) conducive working environment, (2) deep interest towards teaching profession, (3) performing tasks well, (4) satisfactory achievement among students, (5) student factor, and (6) students' understanding during class.

\section{Conducive working environment}

Unequivocally, Malaysian TVET instructors agreed that their satisfaction towards teaching was mainly contributed by the conducive working environment. In fact, a total of 23 quotations $(11.1 \%)$ related to the aforementioned aspect were extracted. For instance, informant 22 affirmed that his/her satisfaction towards teaching is due to the fairness of administrators in fulfilling their duties, teamwork among colleagues, and conducive working environment:

"Informant 22: Fair administrators and understanding, teamwork among colleagues, conducive working environment.” 22:4 (1:248 [1:576]) 
Interestingly, the notion conveyed by informant 22 was parallel to the viewpoint of informant 30 who agreed that his/her satisfaction in teaching is due to the conduciveness of working environment in vocational college and cooperation among colleagues:

"Informant 30: Conducive working environment in vocational college and cooperation among colleagues." 30:5 (1:876 [1:1218]) Consequently, informant 61 explained that his/her satisfaction in teaching is mainly due to the support given by his/her colleagues: "Informant 61: Support from colleagues." 61:2 (1:511 [1:828])

\section{Deep interest towards teaching profession}

Moreover, the thematic analysis revealed that 21 quotations $(10.1 \%)$ were related to the deep interest towards teaching profession. For instance, informant 20 explained that his/her satisfaction toward teaching profession is due to his/her choice of career: "Informant 20: Teaching is my choice of career." 20:1 (1:248 [1:529])

Likewise, informant 32 and 54 reiterated that teaching is indeed their passion: "Informant 32: I really want to be a teacher." $32: 3$ (1:1032 [1:1397]) "Informant 54: Being a teacher is always my interest and soul." 54:4 (1:1704 [1:1938])

\section{Performing tasks well}

On top of that, some Malaysian TVET instructors affirmed that their satisfaction towards teaching was due to their ability to perform tasks well. With reference to the thematic analysis, a total number of 30 quotations (14.4\%) were found to be related to the aforementioned aspect. In particular, informant 15 stated that his/her satisfaction towards teaching was due to his/her achievement in carrying out the tasks given exceptionally: "Informant 15: Able to carry out my duties exceptionally." 15:4 (1:877 [1:1223]) In addition, informant 37 stated that his/her satisfaction towards teaching was the result of attaining his/her work goals: "Informant 37: I've achieved my work goals.” 37:2 (1:511 [1:821])

Similarly, informant 54 stated that his/her satisfaction towards teaching was due to his/her achievement in carrying out planned tasks accordingly: "Informant 54: Able to execute planned tasks." $54: 2(1: 630[1: 958])$

\section{Satisfactory achievement among students}

Besides, 40 quotations (19.2\%) related to the satisfactory achievement among students were extracted among Malaysian TVET instructors understudy. For instance, informant 10 affirmed that his/her satisfaction towards teaching was due to his/her students' satisfactory achievement in academic and co-curriculum despite their small number: "Informant 10: One of the factors that contribute to my satisfaction is when my students excel in academic and co-curriculum. Although it's a small achievement, it means a lot to me" 10:3 (1:345 [1:761])

Undoubtedly, the notion conveyed by informant 10 shared by informant 21 who explained that he/she is satisfied with the teaching profession due to the $100 \%$ passing rate of his/her students: "Informant 21: All my students are passed (100\%)." 21:4 (1:646 [1:959])

Furthermore, both notions of informant 10 and 21 were congruent with informant 31 who disclosed that his/her satisfaction in teaching was due to his ability to produce competent students in his/her field of study: "Informant 31: Whenever I managed to produce competent students for my field." 31:1 (1:248 [1:565])

\section{Student factor}

The Malaysian TVET instructors agreed that their satisfaction towards teaching was also influenced by student-related factors. Through thematic analysis, a total of 11 quotations (5.3\%) related to the aforementioned aspect were extracted. For instance, informant 25 affirmed that his/her satisfaction towards teaching was due to his/her students' commitment: "Informant 25: Students' commitment." 25:3 (1:807 [1:1116])

Meanwhile, informant 47 stated that, his/her satisfaction towards teaching was due to his/her students' development: "Informant 47:
Seeing the positive development of my students." 47:3 (1:940 [1:1298])

Along this line, informant 56 shared that students are indeed one of the factors that made him/her satisfied with the teaching profession: "Informant 56: Students." 56:3 (1:808 [1:1108])

\section{Students' understanding during class}

Equally important, Malaysian TVET instructors agreed that students' understanding during class played a fundamental role in increasing their work satisfaction. Specifically, seven quotations (3.4\%) related to this aspect were extracted. For this particular aspect, informant 19 asserted that his/her satisfaction towards teaching was due to his/her students' understanding during class: "Informant 19: Students are able to understand during class." 19:1 $(1: 248$ [1:518])

Additionally, informant 36 related that his/her satisfaction towards teaching stemmed from the students' diligence in doing the best in their studies: "Informant 36: Student diligence in doing the best that they could." $36: 1$ (1:248 [1:536])

As a matter of fact, informant 59 revealed that he/she gained satisfaction whenever his/her students showed interest and understanding during the lessons in class: "Informant 59: Whenever I see students are interested and understand during class." $59: 2$ (1:341 [1:638])

\section{Discussion}

The place of instructors teaching job satisfaction factor in milieu which is strongly correlated with the Adam's Equity theory as discussed in previous section. Essentially, the bilateral relationship between motivation towards teaching and balance in providing intrinsic and extrinsic values to TVET instructors is significant in achieving teaching job satisfaction. Based on the discussion of job satisfaction factors that were derived from the narrative transcription, it was discovered that the findings support previous researches pertaining to teachers' career. With relation to these findings, it is incumbent on the TVET instructors to determine the factors which enhance their motivation and ultimately encourage them to remain at the TVET institutions

Comprehensively, the working environment which encompasses the school climate, atmosphere and social relationship of instructors is a determinant factor towards instructors teaching job satisfaction. In this study, the conduciveness of a working environment is dependent on numerous factors including the relationship with administrators and colleagues. Previous studies agreed upon the social working environment predict the overall teaching experience at educational institutions that includes self-efficacy, depression problems [14], and burnout [15] among teachers. Evidently, the narrative form of the findings are consistent with prior studies which stated that higher self-efficacy of teachers and idyllic working environment of teachers galvanize the overall teaching job satisfaction and stimulate teachers retention.

Primarily, the subjectivity of working condition reflects the physical environment of the school itself. As reported by Simon and Johnson [16], dissatisfaction among teachers is due to poor working conditions such as lack of facilities, amenities and teaching aids in supporting teaching and learning. Contrary to the findings, physical accommodations and technology which were once a necessity for TVET institutions have been discovered to be irrelevant in this discussion. Besides, outdated machineries and teaching tools of vocational subjects were still being used by some TVET institutions. Clearly, the salience of teaching and learning equipment were inconsistent with prior studies although it was predicted play a major rule to ensure the teaching and learning procedure is effective and meaningful.

Interestingly, the paramount influence of motivated teachers in producing exceptional students' overall performance is evident in the Finnish education system. Undeniably, the Finnish educational system has become exemplary to other nations. To note, Toom and Husu [17] studied the characteristics and atmosphere of Finn- 
ish schools that constituted the overall students' performance and the country with the lowest teachers' attrition rate. Additionally, their analysis revealed that the inclusion of teachers in major decision-making of the school system, the passion to teach, and the degree of enthusiasm and commitment significantly contribute to overall success. Besides, their findings disclosed that the strong passion of TVET instructors towards the teaching profession will naturally be evident through their career prioritization. Also, it is clearly depicted from the transcription that most of the TVET instructors managed to realise and develop their intrinsic values, thus enhancing their understanding of job satisfaction.

On top of that, students' achievement simultaneously contributes to teaching job satisfaction and boost self-efficacy of teachers. Precisely, TVET instructors valued students' achievement and success as reasons for them to consolidate their teaching job satisfaction. To reiterate, another group of researchers highlighted that students' improvement, classroom teaching, learning environment as well as teachers attitude and confidence boost the overall selfefficacy beliefs of teachers [18]. Notably, these researchers disclosed the relativity of intrinsic behavior interconnected with overall teachers' psychological well-being, including personal accomplishment, job satisfaction, and commitment.

Unlike misconceived notions, a teaching career involves challenging responsibilities toward the refinement of human capital in a nation. Therefore, teachers must be competent in order to establish smooth transitions despite facing physically and emotionally demanding situations constantly. In regards to this matter, Aldridge and Fraser [19] raised concern on the self-efficacy of teachers in connection with pressuring and ominous school environment. Specifically, the school climate influences the gamut of intrinsic values that include confidence and the overall job satisfaction. Along these lines, teachers are urged to have a fresh perspective on teacher-student relationship as they are closely associated to student academic outcomes, including achievement in courses (GPA), school behavior (attendance, ODRs), and positive beliefs about schools (academic self-perceptions, valuing school) [20]. As stated above, the overall school climate possesses a direct linkage with the overall job satisfaction of TVET instructors in dealing with teaching and learning processes at TVET institutions.

One of the most common traits of good academic performance which results from the effort and experience of teachers is students' participation in school activities. To achieve this desired state, teachers are given time and opportunity to familiarize and embolden themselves with the school system and ecosystem. Eventually, teachers who possess the right attitude and charisma will successfully enhance students' academic performance and induce students' interest in being at school. For instance, Kraft, Marinell, and Shen-Wei Yee [21] indicated that job satisfaction is a crucial factor in increasing the likelihood of teacher retainment, creating positive vibes among the school organization, and ultimately, enhancing students' achievement. Concisely, TVET instructors generally value students' achievement and seek to enhance their learning process in the classroom.

Equally important, Pedota [22] propitiously claimed that students' belongingness and teacher-student rapport are significant in enhancing teachers' self-confidence and encouraging them to remain in the teaching sector. According to the data procured, TVET instructors' level of concern toward student success affects their self-esteem and the continuity of their interest in teaching.

\section{Conclusion}

In conclusion, this study offers TVET instructors a better understanding of factors which influence teaching job satisfaction and teachers' motivation. Specifically, this research has explored TVET instructors' teaching profession needs in order to sustain and develop their teaching profession. From this study, it was highlighted that job satisfaction comprises of intrinsic and extrinsic factors that determine the overall satisfaction with regards to one's chosen career. Also, the narrative interpretation gathered from the instructors was also acknowledged as the most ideal approach in obtaining TVET instructors' perspectives regarding the teaching profession. Moreover, this method can be applied either directly or indirectly in the curriculum content. As a matter of fact, this research has successfully outlined job satisfaction in several themes and emphasized the need for TVET instructors' teaching preparation program and professional development program (PDP). As fresh teachers are accepted into TVET institutions, ongoing PDP program will provide assistance to ensure that they remain passionate in their profession. Undoubtedly, teachers' competency and disposition are essential components which can complement future projection related to this research paradigm. Notably, in connection with TVET institutions, hopeful individuals are expected to undergo a rigorous selection process at the ministry level. In the process of achieving good sustainability of TVET programs which is aligned to Malaysia's national mission and TVET blueprint, meticulous preparation is required.

\section{Acknowledgments}

This study was supported by grant funding from the Research Management Center, Universiti Putra Malaysia (Grant IPM \#9524400). The assistance of the Educational Planning and Research Division (EPRD), Malaysia and appointed TVET instructors in the data collection process is greatly appreciated.

\section{References}

[1] Billingsley BS (2004), Special education teacher retention and attrition: A critical analysis of the research literature. The Journal of $\begin{array}{lll}\text { Special Education } & 38(1), & 39-55 .\end{array}$ doi:10.1177/00224669040380010401

[2] Gomba C (2015), Why do they stay: Factors influencing teacher retention in rural Zimbabwe? International Journal of Instruction $8(2), 55-68$.

[3] Ingersoll RM (2001), Teacher turnover, teacher shortages, and the organization of schools (No. R-01-1). Seattle: University of Washington, Center for the Study of Teaching and Policy.

[4] Perrachione BA, Rosser VJ \& Petersen GJ (2008), Why do they stay? Elementary teachers' perceptions of job satisfaction and retention. The Professional Educator 32(2), 1.

[5] Boe EE, Cook HL \& Sunderland JR (2008), Teacher turnover: Examining exit attrition, teaching area transfer, and school migration. Exceptional Children 75(1), 7-31.

[6] Brill S \& McCartney A (2008), Stopping the revolving door: Increasing teacher retention. Politics \& Policy 36(5), 750-774. doi:10.1111/j.1747-1346.2008.00133.x

[7] Kearney JE (2008), Factors affecting satisfaction and retention of African American and European American teachers in an urban school district: Implications for building and maintaining teachers employed in school districts across the nation. Education and $U r$ ban Society 40(5), 613-627. doi:10.1177/0013124508316047

[8] Mertler CA (2016), Should I stay or should I go? Understanding teacher motivation, job satisfaction, and perceptions of retention among Arizona teachers. International Research in Higher Education 1(2), 34-45.

[9] Reynolds A \& Wang L (2005), Teacher retention: What role does professional development school preparation play? The New Educator 1(3), 205. doi:10.1080/15476880590966312

[10] Kwiek M \& Antonowicz D (2013), Academic work, working conditions and job satisfaction. In the work situation of the academic profession in Europe: Findings of a survey in twelve countries, 3754. Springer, Dordrecht.

[11] Shin JC \& Jung J (2014), Academics job satisfaction and job stress across countries in the changing academic environments. Higher Education 67(5), 603-620.

[12] Chou CH (2011), Teachers' professional development: Investigating teachers' learning to do action research in a professional learning community. The Asia-Pacific Education Researcher 20(3), 421 437.

[13] Gujarati J (2012 April), A comprehensive induction system: A key to the retention of highly qualified teachers. In The Educational Forum 76(2), 218-223. Taylor \& Francis Group. 
[14] Devos C, Dupriez V \& Paquay L (2012), Does the social working environment predict beginning teachers' self-efficacy and feelings of depression?. Teaching and Teacher Education 28(2), 206-217.

[15] Pyhältö K, Pietarinen J \& Salmela-Aro K (2011), Teacherworking-environment fit as a framework for burnout experienced by Finnish teachers. Teaching and Teacher Education 27(7), 11011110.

[16] Simon NS \& Johnson SM (2015), Teacher turnover in high-poverty schools: What we know and can do. Teachers College Record 117(3), 1-36.

[17] Toom A \& Husu J (2016), Finnish teachers as 'makers of the many' In Miracle of education 41-55. SensePublishers, Rotterdam. Check printed version

[18] Salanova M, Rodríguez-Sánchez AM, Schaufeli WB \& Cifre E (2014), Flowing together: A longitudinal study of collective efficacy and collective flow among workgroups. The Journal of Psychology 148(4), 435-455.

[19] Aldridge JM \& Fraser BJ (2016), Teachers' views of their school climate and its relationship with teacher self-efficacy and job satisfaction. Learning Environments Research 19(2), 291-307.

[20] Suldo SM, McMahan MM, Chappel AM \& Bateman LP (2014), Evaluation of the teacher-student relationship inventory in American high school students. Journal of Psychoeducational Assessment 32(1), 3-14.

[21] Kraft MA, Marinell WH \& Shen-Wei Yee D (2016), School organizational contexts, teacher turnover, and student achievement: Evidence from panel data. American Educational Research Journal 53(5), 1411-1449.

[22] Pedota PJ (2015), How can student success support teacher selfefficacy and retention? Clearing House: A Journal of Educational Strategies, Issues and Ideas 88(2), 54-61. doi: 10.1080/00098655.2014.998600 